\title{
Die Rolle der Habsburgermonarchie in den ersten drei Koalitionskriegen (1792-1809). Eine Fallstudie zur Darstellung der Überwindung von militärischen und politischen Krisen in der Neuzeit
}

\author{
Patrick Plaschg BA \\ Kerngebiet: Österreichische Geschichte \\ eingereicht bei: ao. Univ.-Prof. Mag. Dr. Gunda Barth-Scalmani, \\ Univ.-Prof. Mag. Dr. Scharr Kurt \\ eingereicht im: SoSe 2017 \\ Rubrik: SE-Arbeit
}

\begin{abstract}
The Role of the Habsburg Monarchy in the first three Coalition Wars (1792-1809). A case study illustrating the overcoming of military and political crises in modern times

The aim of this work is to present the military and political role of the Habsburg monarchy in the French Revolutionary Wars and the Napoleonic Wars between 1792 and 1809. Within this belligerent period, the peace treaty of Pressburg, the central event in a series of several peace resolutions, is considered as Napoleon's greatest triumph. Therefore, the path of the Habsburg monarchy to this treaty and the overcoming of the crises of those years represent the central events which are analyzed in this work.
\end{abstract}

\section{Einleitung}

Der Zusammenbruch Österreich-Ungarns am Ende des Ersten Weltkriegs wird das Ende einer europäischen Großmacht darstellen, die diesen Status seit dem Friedensvertrag von Passarowitz' (1718, serb. Požarevac) und damit seit mehr als zweihundert

Gewisse Historiker_innen legen sich aber auch auf die Jahre 1699 oder 1714 fest, in denen die Friedensverträge von Karlowitz, (serb. Sremski Karlovci) bzw. Rastatt (bei Baden-Baden) unterzeichnet wurden; vgl. dazu Thomas 
Jahren innehaben wird. Doch bereits in den ersten Jahren des 19. Jahrhunderts musste die Habsburgermonarchie eine größere Krise überstehen, die diesen Großmachtstatus und ihre Existenz bedrohte. Der Hauptauslöser dieser Krisenphase war eine Serie von militärischen und politischen Niederlagen, die die Habsburgermonarchie und ihre Streitkräfte gegen die Armeen der Französischen Revolution, sprich gegen den französischen General und späteren Kaiser Napoleon Bonaparte erfahren musste. Dennoch, oder vielleicht gerade deswegen, haben Historiker_innen dieser Krisenzeit bisher nur geringe Aufmerksamkeit gewidmet und noch keine umfassende politische und militärische Analyse darüber angefertigt. Da in jenen Jahren aber eine Vielzahl an zentralen militärischen und politischen Weichen gestellt wurden die es der Habsburgermonarchie bzw. ab 1804 dem Kaisertum Österreich ermöglichten, einen wesentlichen Beitrag zum Sturz Napoleons in den Jahren zwischen 1813 und 1815 zu leisten, ist dieser Status umso unzureichender.

Daher ist es das Ziel dieser Arbeit, die militärische und politische Rolle der Habsburgermonarchie in den Kriegen gegen die Französische Revolution zwischen 1792 und 1809 darzustellen, sowie die in diesem Zeitraum durchgeführten Veränderungen im politischen und militärischen Apparat und ihre Auswirkungen auf die Monarchie zu analysieren. Da der Friedensvertrag von Pressburg (slowak. Bratislava, bis 1919 Prešporok) in den historischen Wissenschaften als Napoleons größter Triumph über das Habsburgerreich und als der erste Höhepunkt der Krisenphase gesehen wird, ${ }^{2}$ kann er innerhalb dieser kriegsreichen Periode als zentrales Ereignis in einer Reihe von mehreren Friedensschlüssen betrachtet werden. Daher stellen der Weg der Habsburgermonarchie zu diesem Vertrag und die Überwindung der Krisen jener Jahre einen Schwerpunkt innerhalb der dargestellten Phase dar, der in diesem Werk ebenso analysiert werden wird.

Zur Aufarbeitung dieses Themas werden mehrere Fragestellungen an den Sachverhalt gestellt. Wie war es innerhalb dieses kurzen Zeitraumes für die Habsburgermonarchie möglich, eine derart große Anzahl an Kriegen zu führen? Welche Auswirkungen hatte(n) der(ie) Friedensvertrag(/Friedensverträge) von (Campo Formio, Lunéville und) Pressburg auf die territoriale, politische und militärische Konfiguration bzw. „Verfassung" der Habsburgermonarchie und welche politischen und militärischen Maßnahmen wurden nach diesem(n) Friedensschluss(/Friedensschlüssen) gesetzt, um die Monarchie als entscheidenden „Player" in der Politik Europas zu erhalten?

Die zentrale These dieser Arbeit zu all diesen Fragestellungen lautet wie folgt: Die durch die Friedensverträge erfahrenen territorialen, politischen und militärischen Rückschläge erforderten eine laufende Anpassung und Verbesserung der im 18. Jahrhundert etablierten militärischen und politischen Strukturen der Monarchie. Diese wurden allerdings in evolutionärer Art durchgeführt und die Beibehaltung von be-

Winkelbauer, Die Habsburgermonarchie vom Tod Maximilians I. bis zum Aussterben der Habsburger in männlicher Linie (1519-1740), in: Thomas Winkelbauer (Hrsg.), Geschichte Österreichs, Stuttgart 2016, S. 159-289, hier S. 187-190.

2 Siegfried Fiedler, Taktik und Strategie der Revolutionskriege 1792-1848, Augsburg 2005, S. 74-75. 
währten Elementen im Politik- und Militärapparat aus der Zeit der Kabinettskriege und der Pentarchie hatte weniger Anteil an den erlittenen Niederlagen als bisher angenommen. Trotz der vielfältig geänderten politischen und militärischen Umstände im Zeitalter der Revolutionskriege konnte darüber hinaus eine komplette Niederlage und Zerschlagung der Habsburgermonarchie verhindert und die erwähnten Reformen zu einem späteren Zeitpunkt für einen erfolgreichen Krieg gegen Napoleon umgesetzt und genutzt werden.

Zur Abhandlung dieser These und der Fragestellungen werden einerseits die Inhalte der für die Habsburgermonarchie relevanten Friedensschlüsse der ersten drei Koalitionskriege präsentiert, sowie zu deren weitführenden Analyse die politischen und militärstrukturellen Konsequenzen und deren Veränderungen herausgearbeitet. Zudem wird auch auf die damit verbundenen zentralen politischen und militärischen Entscheidungsträger der Habsburgermonarchie, ihre Handlungen, sowie auf Veränderungen in den höchsten Staatsstellen eingegangen. Dadurch wird die Konstruktion eines politischen und militärischen Gesamtbildes der Monarchie in jenen Jahren möglich, sowie eine Erklärung, wie trotz eines weiteren gescheiterten Krieges gegen das napoleonische Frankreich im Jahr 1809 die Überwindung dieser Krisenzeit bis zu den Befreiungskriegen auf lange Sicht möglich wurde.

Als Grundlage für diese Arbeit wird eine Vielzahl an unterschiedlicher, meist politikund militärhistorischer Literatur, sowie Quellen herangezogen. Als zentrale Quelle ist die Quellenedition von Ernst Walder zu erwähnen, der in dem Werk "Napoleonische Friedensverträge" alle für die Arbeit relevanten Friedensschlüsse in französischer Sprache ediert hat. Doch auch "Der Friede von Pressburg" von Rudolfine Freiin von Oer sowie "Die Schlacht bei Austerlitz" von Christopher Duffy und weitere Beiträge aus Sammelbänden stellen einen westlichen Teil der Literatur dar, die die Erstellung dieses Gesamtbildes ermöglichen.

\section{Die unterschätzte Gefahr (1792-1801)}

\subsection{Die politischen und militärischen Institutionen der Habsburgermonarchie}

Im europäischen Mächtesystem des ausgehenden 18. Jahrhunderts war die Habsburgermonarchie ein zentraler Teil der europäischen Pentarchie. In diesem Mächtegleichgewicht, in dem die fünf europäischen Großmächte, also das russische Zarenreich, das Kurfürstentum/Königreich Brandenburg-Preußen (kurz: Preußen), die Habsburgermonarchie, das Königreich Frankreich und das Königreich Großbritannien in abwechselnden Bündniskonstellationen eine politische Balance herstellen konnten, waren weitreichende Veränderungen dieser politischen Landschaft bis zu den Revolutionskriegen weitgehend unmöglich. ${ }^{3}$

3 Karl Vocelka, Glanz und Untergang der höfischen Welt. Repräsentation, Reform und Reaktion im habsburgischen Vielvölkerstaat (Österreichische Geschichte 1699-1815), Wien 2001, S. 178-179. 
Die für diese außenpolitischen Angelegenheiten zuständigen Behörden und Personen der Habsburgermonarchie waren einerseits der Monarch selbst, der als absoluter Herrscher über die einzelnen Territorien der habsburgischen Erblande galt und somit Verträge mit auswärtigen Mächten abschließen bzw. auch den Krieg erklären konnte. In der Praxis allerdings wurden die Vorgespräche und die Beratungen dazu, sowie die Verhandlungen zu den Verträgen selbst in den einzelnen dafür geschaffenen Gremien der Habsburgermonarchie stellvertretend für den Landesherren geführt. Bei Verhandlungen mit den auswärtigen Mächten wurden daher entweder die zuständigen Vertreter dieser Behörden entsendet oder auch Sonderverhandler ernannt, die dann an bestimmten Verhandlungsorten ihre Gespräche aufnahmen.

Im Jahr 1789 wurde die gesamte Außenpolitik der Erblande von Wenzel Anton Graf von Kaunitz, seit 1764 Reichsfürst von Kaunitz-Rietberg, geleitet, der seit 1753(!) Staatskanzler und damit auch Außenminister der Monarchie war. Unter seiner Gesamtführung entwickelten sich auf institutioneller Ebene zwei zentrale Behörden heraus, die mit den wichtigsten Agenden der Staatsführung und der Außenpolitik betraut wurden. Einerseits war dies die Geheime (Haus-), Hof- und Staatskanzlei, welche dreißig Bedienstete umfasste (1792) und als zentrale Behörde für die Außenpolitik und die Diplomatie mit dem Staatskanzler an der Spitze diente. Andererseits gab es den 1760 geschaffenen Staatsrat, der drei Mitglieder zählte und das zentrale Beratungsgremium des Monarchen in allen außen- und innenpolitischen Angelegenheiten war. Beide Institutionen waren in den Jahren unter Maria Theresia und ihrem Sohn Kaiser Joseph II. reformiert und ausgebaut worden und für ihre Zeit leistungsfähige Zentralbehörden mit Sitz in Wien und hatten erfahrenes Personal, das meist mit Abgängern der k.k. Akademie für Orientalische Sprachen in Wien besetzt war. ${ }^{4}$

Auf dem Gebiet des Militärwesens setzte sich im 18. Jahrhundert das System der sogenannten Kriegskabinette durch. Das zentrale Kabinett für die Kriegsführung im Habsburgerreich war der Hofkriegsrat. Diese Institution, die bereits seit 1552 bestand, kümmerte sich in mehreren Sektionen um alle Angelegenheiten der Armee, wie u. a. die Finanzierung, Proviantierung und Ausrüstung, und war zudem die zentrale Schaltstelle zwischen der Generalität im Feld und dem Monarchen und seinen Ministern in Wien. Im Jahr des Kriegsbeginnes (1792) hatte der Hofkriegsrat zwischen drei und sechs militärische und zehn zivile Hofkriegsräte mit weiterem Personal wie Schreibern usw., was im Zeitalter der begrenzten Kriegsführung der Kabinettskriege ausreichend war. Doch in Anbetracht der Menge an Aufgaben und angesichts einer komplexen Geschäftsordnung musste dies, trotz aller Zentralität, in langen Kriegszeiten zwangsläufig zu einem Arbeitsstau und damit auch zu einer absehbaren Reformnot führen. ${ }^{5}$

Den zentralen Part zur Ausführung und Durchsetzung aller außenpolitischen Interessen stellte die kaiserlich-habsburgische Armee dar, die unabhängig vom nur im Kriegsfall aufgestellten Reichsheer, über das die Habsburger über den Kaisertitel des

$4 \quad$ Vocelka, Glanz und Untergang, S. 354-361.

5 Oskar Regele, Der österreichische Hofkriegsrat 1556-1848 (Mitteilungen des österreichischen Staatsarchivs I), Wien 1949, S. 42-43. 
Heiligen Römischen Reiches Deutscher Nation theoretisch ebenso verfügen konnten, die Haustruppe der Habsburgermonarchie darstellte. Bereits in der Zeit vor 1789 hatte dieses Heer als wesentlicher Baustein gegen die französische Vormacht am Kontinent gedient, so zum Beispiel im Spanischen, Polnischen und Österreichischen Erbfolgekrieg, war später auch im Bündnis mit Frankreich an den Schlesischen Kriegen bzw. im Siebenjährigen Krieg gegen die preußische Expansion beteiligt und somit auch für die Herstellung eines militärischen Gleichgewichtes am Kontinent verantwortlich. Zudem wurden die habsburgischen Truppen in der Zeit nach 1765 durch weitere Reformen und Aufbaumaßnahmen zur wesentlichen militärischen Macht am Kontinent, welche durch die weiteren Erfahrungen in den folgenden Kriegen, wie dem Bayrischen Erbfolgekrieg und dem Türkenkrieg von 1788-1791, einem durch die Maria Theresianische Militärakademie gut ausgebildetem Offizierskorps und einer zeitgemäßen Bewaffnung in allen Waffengattungen weitere Verbesserungen erhielten. ${ }^{6}$ Um 1790 war sie die schlagkräftigste Armee des Kontinents mit einer Kriegsstärke von ca. 315.000 Mann in 74 Infanterie- und 33 Kavallerieregimentern und weiteren Einheiten, wie Artillerieregimentern und technischen Truppen.?

Auch in der Art der Kriegsführung war die kaiserlich-habsburgische Armee auf der Höhe der Zeit und praktizierte die Art des Kampfes mit der damals üblichen Taktik des mehrfach gestaffelten Liniengefechtes, in dem meist über die Angriffe an den Flügeln die Entscheidung fiel. In den letzten Jahren vor der Französischen Revolution wurden zudem vermehrt leichte Truppen (auch „Jäger" genannt) in die Gefechtstaktik eingeführt, welche bereits in Vorgeplänkeln eine Vorentscheidung erzielen sollten. Ihre Existenz sollte sich in den folgenden Jahren als ein entscheidender Vorteil im Kampf mit den französischen Truppen herausstellen und war daher auch ein wesentlicher Ausgangspunkt für zukünftige Reformen. ${ }^{8}$

Doch trotz dieser funktionierenden institutionellen und strukturellen Voraussetzungen, die außenpolitische Entscheidungen grundsätzlich schnell durchsetzungsfähig machen sollten, konnte die Habsburgermonarchie ihre seit den 1750er-Jahren bestehenden Bündnisverpflichtungen (Stichwort: „Renversement des alliances”) mit dem Königreich Frankreich im Kampf gegen die Revolution nicht erfüllen. Dies hatte zur Folge, dass die Revolution bis zum Jahr 1792, mit der erzwungenen Abdankung von König Ludwig XVI., das gesamte System des Ancien Régime in Frankreich zerstören konnte. Die Gründe für die anfängliche Untätigkeit der Monarchie lagen einerseits an der schlichten Unterschätzung der Auswirkungen und Folgen dieser Revolution im Beraterkreis des Kaisers, welche lediglich durch Staatskanzler Kaunitz und einige Generäle erkannt wurden. Andererseits lag es auch an einer innenpolitischen Krise der Monarchie, die sie in den entscheidenden Monaten nach der Revolution nur bedingt handlungsfähig machte. Dies wird durch einen dreimaligen Thronwechsel innerhalb von nur zwei Jahren deutlich, der auch außenpolitische Konsequenzen hatte. Denn

Siegfried Fiedler, Taktik und Strategie der Kabinettskriege 1650-1792, Augsburg 2005, S. 7-9.

Michael Hochedlinger, Austria's Wars of Emergence. War, State and Society in the Habsburg Monarchy 1683-1797 (Modern Wars in Perspective), London-New York 2013, S. 300-301. 
auf Kaiser Joseph II. folgte 1790 sein Bruder Leopold II., der in seinem aufklärerischen Gedankengut mit vielen Teilen der Revolution sympathisierte. Doch bereits 1792 kam nach Leopolds Tod dessen Sohn Franz II. an die Macht, der zwar konservativ, konterrevolutionär und auch kriegsbereit, dafür aber unerfahren war und sich mit Kaunitz in einem dauerhaften politischen Zwist befand. Ein weiterer Faktor war der militärisch und finanziell belastende Türkenkrieg, sowie ein Aufstand der Provinz Brabant in den Österreichischen Niederlanden, was die, aus diesen militärischen Einsätzen resultierenden, hohen Schulden des Staates (die Militärausgaben lagen 1789 bei ca. siebzig Mio. Gulden, im Vergleich 1778: ca. zwanzig Mio. Gulden) in die Höhen trieb, sodass die Truppen bereits 1791 durch Leopold II. auf ca. 215.000 Mann reduziert werden mussten. $^{10}$

Trotzdem stellten diese Maßnahmen aus finanzieller Perspektive eine nachvollziehbare Handlung dar und ob eine sofortige Invasion eine schnelle Entscheidung zugunsten der Royalisten gebracht hätte, mag stark bezweifelt werden. Zudem wurde die Zeit zwischen 1789 und 1792 dennoch genutzt, um politisch und militärisch auf einen immer wahrscheinlicher werdenden Krieg vorbereitet zu sein. So konnte Kaiser Leopold II. in den letzten Wochen seiner Regierungszeit mit der Pillnitzer Fürstenversammlung, auf der die gleichnamige Deklaration (17. August 1791) beschlossen wurde, die sogenannte "Zweite diplomatische Revolution" einleiten, die ein Bündnis mit dem bisherigen „Erbfeind” Preußen vorbereitete. Im März 1792 wurde dieses Bündnis zu einem vollwertigen Vertrag aufgewertet und gegen den Willen von Kaunitz abgeschlossen, der dies verhindern wollte, da es seinen Vertrag von 1754 mit Frankreich außer Kraft setzte und er aufgrund der schlesischen Kriege grundsätzlich ein entschiedener Gegner Preußens war. In dieser Abkehr kam es damit auch zu einer ersten relevanten Reform der Politik des Habsburgerreiches seit Mitte des 18. Jahrhunderts. Sie band König Friedrich Wilhelm II. und seinen preußischen Staat in ein Bündnis an die Habsburgermonarchie, das trotz einiger Unterbrechungen (siehe dazu nächstes Kapitel) bis in die 1860er-Jahre anhalten bzw. auch in den Zwischenphasen Preußen in die Neutralität zwingen sollte. Gemeinsam konnten beide Monarchien ab dem Frühjahr 1792 einen militärischen Aufmarsch für eine Wiedereinsetzung der „alten“ Herrschaftsverhältnisse in Frankreich starten. ${ }^{11}$

\subsection{Der Erste Koalitionskrieg}

Doch in Frankreich hatten die revolutionären Kräfte insoweit ihre Kräfte bündeln können, indem sie, wie von Kaunitz befürchtet, diese Mächte des „Alten Europa“ zu ihrem gemeinsamen Feind erklärten und somit einen Sturm von Patriotismus in Frankreich auslösten. Nachdem die Nationalversammlung in Paris großen Druck auf König Ludwig XVI. ausgeübt hatte, erklärte dieser am 10. April 1792 dem eigentlich noch immer verbündeten Habsburgerreich den Krieg. Preußen sollte seinerseits wenige Tage später

$9 \quad$ Hochedlinger, Austria's Wars, S. 286.

10 Ebd., S. 300.

11 Elisabeth Fehrenbach, Vom Ancien Régime zum Wiener Kongress (Oldenbourg Grundriss der Geschichte 12), München 2008, S. 45. 
folgen, was den ersten Koalitionskrieg auslöste. Nur kurze Zeit später (19. August 1792) trat auch Kaunitz von all seinen Ämtern zurück und machte den Weg frei für einen politischen Neustart. Kaiser Franz II. wollte nach der Kriegserklärung die Revolution mit einem schnellen militärischen Sieg der Koalition beenden, wofür mit Philipp Graf von Cobenzl und Anton Spielmann bzw. nach deren schnellen Ablösung (wegen des Versagens der außenpolitischen Leitung in der zweiten Polnischen Teilung, bei der die Habsburgermonarchie leer ausging) im Jahr 1793 mit Johann Amadeus Franz von Thugut neue Personen für die Leitung der äußeren Beziehungen und der Kanzlerposition bestellt wurden, die bereit waren diesen Kurs mitzugehen. ${ }^{12}$ Zudem wurde 1792 mit dem Geheimen Kabinett im außenpolitischen Sektor eine erste strukturelle Reform umgesetzt, die die außenpolitischen Entscheidungen der Behörden kommentieren und damit kontrollieren sollte, noch bevor diese dem Kaiser zum endgültigen Entschluss vorgelegt wurden. Diese Art der außenpolitischen „Qualitätssicherung" hatte Franz Karl Graf von Colloredo-Waldsee zu organisieren, der in den folgenden Jahren diesem Kabinett vorstand. ${ }^{13}$

Um die von der neuen und zum Teil bereits umstrukturierten außenpolitischen Leitung gesteckten Ziele umzusetzen, wurde im Sommer 1792 eine Offensive der Verbündeten in das Kernland Frankreichs aus mehreren Angriffsrichtungen gestartet. Doch nach einem Sieg der kaiserlich-habsburgischen Truppen bei Lamain ${ }^{14}$ in Nordfrankreich, der der Disziplin ihrer Truppen zu verdanken war, kam im Herbst die Wende, da die Revolutionsgeneräle ihre Truppen aufgrund von Führungs- und Nachschubproblemen bei den Alliierten sammeln konnten. Sowohl bei Valmy (20. September) als auch Jemappes (6. November), kam es in der Folgezeit zu entscheidenden Niederlagen der Koalition, die in einem Rückzug über die Grenzen Frankreichs endeten. Für wenige Monate gelang es den französischen Revolutionsarmeen sogar, Teile der Österreichischen Niederlande zu erobern. Nach diesen Niederlagen zog sich Preußen aus den offensiven Handlungen zurück und beließ nur wenige Truppen zum Schutz der deutschen Gebiete am Rhein. Ab 1793 lag daher die gesamte militärische Last nahezu ausschließlich auf den Truppen des Hauses Habsburg. Dazu wurde die Anzahl der Soldaten auf nahezu fünfhunderttausend Mann angehoben, was zeigt, dass auch ohne Einführung einer Wehrpflicht eine große Masse an Soldaten mobilisierbar war. Zudem gelang es für kurze Zeit sogar, u. a. im Großherzogtum Baden, eine Bürgermiliz zu formen, die erfolgreich Einfälle der Revolutionsarmeen abwehren konnte, was verdeutlicht, dass habsburgische Generäle, wenn auch ohne langfristigen Erfolg, an einer Umsetzung einer Art Volkskriegsführung arbeiteten. Dafür waren allerdings die Kriegskosten innerhalb kürzester Zeit auf über hundert Mio. Gulden angewachsen, was den Staatshaushalt weiter belastete. ${ }^{15}$

\footnotetext{
Hochedlinger, Austria's Wars, S. 420.

Erwin Matsch, Geschichte des auswärtigen Dienstes von Österreich(-Ungarn) 1720-1920, Graz 1980, S. 69-70.

Vocelka, Glanz und Untergang, S. 178.

Ebd., S. 285.
} 
Trotzdem war diese Strategie in der Folgezeit erfolgreich. Denn einerseits konnte durch die Kriegserklärung Frankreichs an Großbritannien ein weiterer Verbündeter gewonnen werden (dessen Verbundenheit ebenfalls bis weit ins 19. Jahrhundert andauern sollte), der ab diesem Zeitpunkt mit Zahlung von Subsidien den Krieg der Verbündeten entscheidend unterstützen konnte, und andererseits konnten auch die Reichsstände von den zuständigen Gesandten der Staatskanzlei zur Erklärung des Reichskrieges gegen Frankreich überzeugt werden (22. März), was zudem die intensiven und erfolgreichen außenpolitischen Aktivitäten der Monarchie in jenen Jahren belegt. Im Sommer 1793 wurde durch drei entscheidende Siege in den Schlachten bei Neerwinden, Famars und bei Pirmasens auch auf der militärischen Ebene die Situation zugunsten der Alliierten gewendet. Doch bereits das nächste Jahr brachte mit der Einführung der Wehrplicht in Frankreich (genannt "levée en masse"), verbunden mit der Durchsetzung des „Tirailleurgefechtes" als eine radikalere Art des Jägergefechtes, bereits eine erneute Wende im Kriegsverlauf. Denn das Heer Frankreichs wurde ab diesem Zeitpunkt neben den Freiwilligen jährlich auch mit einer großen Anzahl an neuen Rekruten aufgestockt, die dort ihre Pflichtleistung für den Staat abdienen mussten. Dies führte dazu, dass die französischen Truppenkommandeure noch rücksichtsloser mit Mensch und Material umgingen und Offensiven damit länger und umfangreicher durchführen konnten. So fielen nach der für sie gewonnenen Schlacht bei Fleurus (26. Juni 1794) zuerst die Österreichischen Niederlande an die französischen Streitkräfte, während im folgenden Jahr bereits die Rheingrenze überschritten wurde. Doch die habsburgischen Oberbefehlshaber lernten auch mit diesen Taktiken relativ schnell umzugehen. Durch Erfolge, wie zum Beispiel bei Handschuhsheim (24. September 1795), Mannheim (18. Oktober) oder Mainz (29. Oktober), die die habsburgischen Verbände ihrerseits hauptsächlich durch den Einsatz von Jägerverbänden bzw. durch den „leichten" Krieg gewinnen konnten, war eine erfolgreiche Stabilisierung der Lage möglich. Auch im Jahr 1796 gelang es dem jüngeren Bruder des Kaisers, Feldmarschall Erzherzog Karl, die Franzosen durch den kombinierten Einsatz von Linieninfanterie und Jägertruppen in mehreren Schlachten, wie zum Beispiel bei Amberg und Würzburg, zu schlagen und sie über den Rhein zurückdrängen. ${ }^{16}$

Doch im selben Jahr war mit General Napoleon Bonaparte ein neuer Typ Heerführer an die Spitze der französischen Armee in Italien berufen worden, der den rücksichtlosen Krieg, die Geschwindigkeit der Gefechtsverlagerung, aber auch die Propaganda um das militärische Geschehen auf ein neues Level hob. In mehreren Schlachten, u. a. bei Mondovi, Lodi und Arcole, brachte er innerhalb eines Halbjahres das von habsburgischen Truppen beherrschte Gleichgewicht des späten 18. Jahrhunderts in (Nord-) Italien zu Fall und marschierte innerhalb weniger Monate an die Grenze der habsburgischen Territorien. Auch der von Thugut ausgearbeitete Plan, die italienischen Staaten in ein großes militärisches Bündnis mit dem Habsburgerreich zu bringen, scheiterte am schnellen Vormarsch Napoleons und seinem politischen Engagement. Erst der aus

16 Fiedler, Taktik und Strategie der Revolutionskriege, S. 197-206. 
den deutschen Territorien herbeigerufene Erzherzog Karl konnte unter dem Aufgebot von leichten Truppen und der Initiierung von Aufständen in Napoleons Rücken, diesen im folgenden Jahr in Leoben vorläufig stoppen und dort einen Waffenstillstand unterzeichnen (18. April 1797). ${ }^{17}$

Obwohl eine Entscheidungsschlacht ausgeblieben war, wurde Kaiser Franz II. vor vollendete Tatsachen gestellt und daher gezwungen, den (vorläufigen) Frieden von Campo Formio zu schließen, der am 17. Oktober 1797 von den Gesandten des Kaisers Johann Ludwig Graf von Cobenzl, Generalmajor Maximilian Friedrich Graf von Merveldt und Baron Ignaz von Degelmann unterzeichnet wurde. In den darin enthaltenen 25 Artikeln (plus 17 Geheimartikeln!), setzte Napoleon seine Forderungen für Frankreich weitgehend durch, was nicht nur an der demonstrierten militärischen Überlegenheit Napoleons lag, sondern auch an seinen politischen Freiheiten, die ihm das Direktorium in Paris ließ. Auf der Gegenseite herrschte dagegen Ernüchterung und Uneinigkeit, was auch durch unterschiedliche und widersprüchliche Anweisungen für die Gesandten aus den Zentralbehörden in Wien verursacht wurde. Daher und aufgrund des Inhaltes des Vertrages wurden die unterzeichneten Bedingungen auf der habsburgischen Seite weitgehend als Niederlage empfunden. Trotzdem wird bei einer Analyse des Inhaltes klar, dass einige Punkte auch gewisse Vorteile für die Monarchie beinhalteten. Denn ein wichtiger Eckpfeiler von Campo Formio für die Habsburgermonarchie war die zunehmende Arrondierung ihrer Gebiete, die bereits unter Kaiser Joseph II. begonnen hatte, die sich aber wegen der Strukturen der Diplomatie des 18. Jahrhunderts nie vollständig durchsetzen hatte können (Stichwort bayrisch-niederländisches Austauschprojekt). Durch die Erlangung Venetiens und Dalmatiens (Artikel VI.) konnte dies auf italienischem Boden vorläufig umgesetzt werden. Im Gegenzug arrangierte sich die Habsburgermonarchie über die Abgabe der Österreichischen Niederlande (Art. III.), die in den militärischen Planungen seit fast einhundert Jahren einen wesentlichen Nachteil bedeutet hatten, der Lombardei (Art. VIII.) und weiteren Verschiebungen an der Reichsgrenze (Artikel XVIII., bzw. Geheimart. I.) mit Frankreich. Diese Gebietsverluste wurden v. a. auch durch den Erwerb von Westgalizien akzeptabel, welcher über die Vermittlungsgeschicke Thuguts bereits im Jahr 1795 erfolgt war (dritte polnische Teilung) und eine erhebliche Erweiterung der Habsburgermonarchie im Osten darstellte. Dadurch wird neben der Arrondierung der Erblande auch ein verstärkter (Nord-)Osttrend für die Habsburgermonarchie erkennbar. Dagegen konnte die Annexion von Salzburg und Bayern nicht durchgesetzt werden, wurde aber ebenfalls in den Geheimartikeln für einen späteren Friedenschluss niedergeschrieben, was definitiv ein Etappensieg für die habsburgischen Unterhändler war. Die restlichen Artikel des Vertrages befassten sich mit den üblichen Formalitäten, wie dem Austausch von Kartenmaterial, Handels- und Schifffahrtsrechten, Eigentumsrechten einzelner Personen und Stände, dem Gefangenenaustausch und der Anweisung, einen auch für das Heilige Römische Reich und Frankreich bindenden Friedensvertrag zu schließen. All diese Vertragsteile waren be-

17 Alan J. Reinerman, The Papacy, Austria, and the Anti-French struggle Italy. 1792-1797, in: Kinley Brauer/William E. Wright (Hrsg.), Austria in the Age of the French Revolution 1789-1815, Minneapolis 1990, S.47-68, hier S. 51-59. 
reits seit dem späten 17. Jahrhundert Teil von Friedensverträgen und daher genauso wie die im Schlussartikel erwähnten Ratifizierungsanweisungen keine Neuerungen. ${ }^{18}$

Darauf aufbauend sind über die Vertragsebene hinaus v. a. die militärischen Ergebnisse und Folgen des Ersten Koalitionskrieges neu zu betrachten. Denn obwohl eine Invasion Frankreichs und die Wiedereinsetzung der Bourbonen gescheitert war, waren die Jahre 1793, 1795 und 1796 positiv verlaufen. Das zu zögerliche Vorgehen in der Offensive und die größeren Niederlagen waren weitgehend der mehrfachen Neubesetzung des Postens des Oberbefehlshabers durch den Kaiser und den Hofkriegsrat bzw. den Finanz- und Materialmängeln in der Armee geschuldet, sowie einer dauerhaften zahlenmäßigen Unterlegenheit nach dem Ausscheiden Preußens und der norddeutschen Reichsstände aus dem Krieg im Jahr 1795. Trotzdem war es in der defensiven Kriegsführung gelungen, den französischen Generälen und ihren Massenheeren mit den angepassten Taktiken der Linien- und Jägerkriegsführung als ebenbürtig und in einigen Schlachten sogar überlegen zu sein. Nur im Vergleich mit Napoleon und den neuen rücksichtsloseren Kampftaktiken wurde die Unterlegenheit dieser Truppe offengelegt. ${ }^{19}$

All diese Faktoren wurden auch in den Leitungsgremien des Hofkriegsrates (unter den Leitern Graf Wallis 1791-1795 bzw. Graf Nostitz-Rieneck 1795-1796 und Graf Tige 1796-1801 ${ }^{20}$ so analysiert, doch Änderungen wurden bis zum Ende des Krieges weitgehend aufgeschoben. Größere Reformen wurden, obwohl Erzherzog Karl bereits während des Krieges auf umfangreiche Reformen drängte, auf die Zeit nach einem endgültigen Friedensvertrag aufgeschoben. So wurde die lange geplante Einführung eines neuen Infanteriegewehres (M.1798, eine Weiterentwicklung der seit 1753! verwendeten "Comissflinte" bzw. des französischen Modells M.1777) erst 1798 durchgeführt, was die zeitgleiche Einführung eines neuen "Stutzens" (Kurzfeuerwaffe) für die Kavallerie und die Jäger durch die dazu berufene Alvintzy-Kommission unter ihrem Leiter Feldzeugmeister Joseph Freiherr von Alvintzy beinhaltete. Zudem konnte eine neue Uniformierung umgesetzt werden, die statt dem sog. "Casquet” einen Infanteriehelm und statt dem „Füsiliersäbel“ ein neukonstruiertes Bajonett für den Nahkampf vorsah und die kürzere Rockschössel und höhere Stehkrägen beinhaltete. All diese Reformen wurden unter den Erfahrungen der neusten Waffentechnik durchgeführt, was damit weitere Vorteile für die Zukunft bot. Tatsächlich war die Qualität des Gewehres so gut, dass diese Waffe, so wie die meisten Änderungen an der Ausrüstung in diesem kurzen Zeitfenster, bis 1830/48 zum Standard innerhalb der Streitkräfte des Kaisertums Österreichs wurden und danach mit nur geringfügigen Änderungen bis 1867 weiterhin beibehalten wurden. Dies verdeutlicht die Qualität der in diesem Zeitfenster gemachten Reformen und bildete eine Grundlage für die Kriegsführung der kaiserlichen habsburgischen Armee in der Zukunft. ${ }^{21}$

18 Ernst Walder (Hrsg.), Napoleonische Friedensverträge. Campo Formio 1797 - Lunéville 1801 - Amiens 1802 Preßburg 1805 - Tilsit 1807 - Wien-Schönbrunn 1809, Bern 1973², S. 10-15.

19 Fiedler, Taktik und Strategie der Revolutionskriege, S. 123-124.

20 Regele, Der österreichische Hofkriegsrat, S. 77.

21 Georg Ortenburg, Die Waffen der Revolutionskriege 1792-1848, Augsburg 2005, S. 45-57. 
Insgesamt gesehen wäre diese Strategie mit einer anschließenden längeren Friedensperiode und weiteren Reformen sicherlich noch erfolgreicher verlaufen. Doch der entscheidende Fehler in jenen außenpolitischen Kalkulationen wurde mit der Unterschätzung von Napoleons politischem Potenzial, genauso wie seiner Eigenschaft, gut organisierte Massenheere zu führen, gemacht, was in der Folgezeit zu weiteren Kriegen führen würde.22

\subsection{Der Zweite Koalitionskrieg}

Der für 1799 geplante Rastatter Frieden für Gesamteuropa scheiterte noch im selben Jahr, da auf Betreiben Großbritanniens und des Zarenreiches der Zweite Koalitionskrieg ausbrach. Die Habsburgermonarchie, die sich durch die im Frieden von Campo Formio entstandenen französischen Tochterrepubliken in (Ober-)|talien ebenso bedroht sah, wurde durch einen von Staatskanzler Thugut genehmigten russischen Truppendurchmarsch durch die Monarchie ebenfalls in diesen Krieg hineingezogen. Denn die Kriegserklärung Frankreichs an die Habsburgermonarchie erfolgte aufgrund dessen am 12. März 1799. Die Abwesenheit Napoleons, der nach der Niederlage der französischen Flotte in der Seeschlacht von Abukir in Ägypten festgesetzt war, ermöglichte allerdings eine schnelle Offensive der russischen und habsburgischen Truppen in Süddeutschland, Italien und auch in der Schweiz gegen die vorgedrungenen französischen Verbände. In mehreren Schlachten, wie jenen bei Ostrach (21. März), Stockerach (25. März), Magnano (05. April), Cassano (27. April) oder in der ersten Schlacht bei Zürich (04. Juni) wurden die französischen Verbände abermals nach dem Muster der angepassten Linienkriegsführung geschlagen und mussten ganz Süddeutschland und Norditalien räumen. Sogar die Position in der Eidgenossenschaft war für sie mittlerweile in Gefahr geraten. Die dargestellten Ereignisse des Jahres 1799 verdeutlichen daher nochmals, dass die Schlagkraft der angepassten Taktiken des habsburgischen Heeres nach wie vor im Jahr 1799 noch nicht überholt war und in Verbindung mit den vorangegangenen Materialreformen und einer klaren Strategie der Oberbefehlshaber sogar einen wesentlichen Vorteil ermöglichte. ${ }^{23}$

Doch die unklare außenpolitische Linie Kanzler Thuguts und die schlechte Kommunikation innerhalb der Koalition verschlechterte die Beziehungen zum Zarenreich so sehr, dass der Zar das Bündnis im Herbst 1799 aufkündigte. Damit war die Habsburgermonarchie im Jahr 1800 erneut der einzige Gegner Frankreichs am Kontinent. Napoleon war bereits im selben Jahr nach Frankreich zurückgekehrt und konnte sich in einem Staatsstreich zum ersten Konsul Frankreichs durchsetzen, hatte damit erneut umfangreiche Vollmachten für einen Feldzug. Nach diesem politischen Schachzug begab er sich zu den Truppen und marschierte überraschend über den Bernina Pass nach Italien. Dort siegte er in der Schlacht bei Marengo (14. Juni 1800), während sein Kollege JeanVictor Moreau nur wenige Monate später bei Hohenlinden (3. Dezember) eine weitere

22 Fritz Baer, Zum Reformwerk des Kriegsministers Generalissimus Erzherzog Karl, in: Fritz Hans Baer (Hrsg.), Die k.k. österreichische Armee im Kampf gegen die französische Revolution und Napoleon I., Wien 1989, S. 45-64, hier S. 49. 
habsburgische Armee schlagen und ähnlich wie Napoleon 1797 bis an die Grenze von Österreich unter der Enns marschieren konnte. Diese Ereignisse brachten die Habsburgermonarchie innerhalb weniger Wochen nicht nur um nahezu alle im Vorjahr errungenen Erfolge, sondern zwangen Thugut, Friedensgespräche mit Napoleon in einem strategisch ungünstigen Moment aufzunehmen. ${ }^{24}$

Der darauffolgende Friede von Lunéville (9. Februar 1801) wurde in insgesamt 22 Artikeln (mit weiteren Geheimartikeln) niedergeschrieben, wodurch er damit deutlich kürzer wurde als der vorangegangene Frieden von Campo Formio. Nach einer allgemeinen Einleitung, die der des Friedens von Campo Formio sehr ähnlich war (also der formellen Bekundung des Wunsches nach ewigem Frieden, die Nennung der Bevollmächtigten aller Parteien, usw.), musste der nach Lunéville entsandte kaiserliche Diplomat Graf von Cobenzl in Artikel II. die Übertragung der Gebiete der ehemaligen Österreichischen Niederlande endgültig akzeptieren und der Abtretung weiterer Gebiete am Rhein, wie der Grafschaft Falkenstein und dem Fricktal, zustimmen. Zudem wurde in Artikel III. eine Abtretung des westlichsten Teiles des 1797 gewonnenen Venetiens verfügt und eine neue Grenzlinie entlang der Etsch (ital. Adige) gezogen. In Artikel IV. wurde das bis dahin habsburgische Breisgau an die Herzöge von Modena verfügt, wodurch das letzte politische und militärische Standbein der Habsburger im Westen des Reiches endgültig zerstört worden war. In Artikel VI. wurde auch eine weitere Schwächung des Reiches durchgesetzt, welches nun endgültig seine Gebiete westlich des Rheins an Frankreich abtreten musste. Damit verbunden regelte Artikel VII. den Umgang mit den landlosen Fürsten des Reiches, die rechtsrheinisch entschädigt werden sollten, sowie die Entschädigung des Fürsten der Toskana, der einer habsburgischen Seitenlinie angehörte und in Artikel V. Herrschaft und Rechte über die Toskana abtreten musste. Zudem wurden die Satellitenstaaten der französischen Republik, wie die helvetische, batavische, cisalpinische und ligurische Republik, von der Habsburgermonarchie anerkannt, was eine weitere territoriale Verschlechterung für die Monarchie für die nahe Zukunft bedeutete (Art. XI.). Weiterführend wurde der Geheimartikel von Campo Formio, der die Entschädigung der Monarchie mit Bayern und Salzburg festlegt hatte, wieder gestrichen, was eine entscheidende territoriale Zäsur auch in Richtung Deutschland bedeutete. Die letzten Artikel beziehen sich, ähnlich wie der Friedensvertrag von Campo Formio, auf den Austausch der Gefangenen, die Rechte an der Schifffahrt auf der Etsch und auf die Art und Zeitspanne, in der die Ratifikation der Urkunden stattfinden sollte. Zudem wird in Artikel XVII. dezidiert auf mehrere Punkte von Campo Formio und deren unwiderrufliche Gültigkeit verwiesen. ${ }^{25}$

All diese Tatsachen verdeutlichen, dass der Friedensvertrag von Lunéville aus diplomatischer Perspektive eine erweiterte Version des Friedens von Campo Formio war, aber mit wesentlich verschlechterten Bedingungen für die Monarchie. Denn der Inhalt ermöglichte eine entscheidende Machtausdehnung Frankreichs und eine Zurückdrän-

24 Brigitte Mazohl, Vom Tod Karls VI. bis zum Wiener Kongress (1740-1815), in: Thomas Winkelbauer (Hrsg.), Geschichte Österreichs, Stuttgart 2016, S. 290-358 hier S. 312-314. 
gung der Habsburgermonarchie, was definitiv neues Konfliktpotenzial beinhaltete. So hatte auch Kanzler Thugut, der bis zum Ende des Krieges keine klare außenpolitische Linie gezeigt hatte und damit in seiner Politik gescheitert war, bereits im September 1800 zurücktreten müssen. Genauso traf es Hofkriegsratspräsident Tige, der wenig später ebenfalls demissionierte. Doch trotz all dieser negativen Stimmung in Wien, veranschaulicht ein Vergleich der Gebietsverluste mit den Gebietsgewinnen, ein divergierendes Bild der Situation im Jahre 1801. Denn der Habsburgermonarchie waren in diesem Krieg erneut größere Gebietsverluste erspart geblieben (was auf Kosten des Reiches ging) und der Vertrag von Lunéville war aus territorialer Perspektive nicht nur eine Anerkennung der Waffenleistung der Habsburgermonarchie durch Napoleon, sondern auch ein Zeichen, dass die außenpolitische Leitung das Projekt einer Arrondierung der Habsburgermonarchie weiterführen konnte und die leitenden Personen in Wien begonnen hatten, eine Konzentration der militärischen und außenpolitischen Kräfte herbeizuführen. ${ }^{26}$

\section{Die Wendejahre einer Großmacht und der Dritte Koalitionskrieg (1801- 1805)}

\subsection{Die erste Reformperiode (1801-1804)}

Bereits wenige Wochen nach dem Frieden von Lunéville begann in den zuständigen Behörden eine intensive Diskussion, wie nach dieser Niederlage die zentralen Stellen der Heeresorganisation bzw. der Staatsführung verbessert werden könnten. Führend in all den Planungen war Erzherzog Karl, der mit dem von ihm beeinflussten kaiserlichen Reskript vom 9. Jänner 1801 die sogenannte Erste Reformperiode des Politikund Militärwesens der Monarchie einleitete. Der erste Schwerpunkt lag daher auf den außenpolitischen Institutionen, die nach fast zehn Jahren Reformstau entscheidende Umstrukturierungen erfahren sollten, um eine effektive Kriegsführung gegen das revolutionäre Frankreich und dessen Massenkriegsführung in Zukunft zu ermöglichen. ${ }^{27}$

So wurden der Staatsrat und das Geheime Kabinett als Beratungs- und Kontrollgremien der Außenpolitik abgeschafft und dafür eine neue Behörde eingerichtet. Diese neue Behörde wurde Staats- und Konferenzministerium genannt und durch die Übernahme des Personalstandes des Staatsrates am 31. August 1801 aktiviert. Sie sollte unter der Leitung von Colloredo, der auch neuer Staatskanzler wurde, alle für die Verteidigung und Außenpolitik der Monarchie nötigen Personen institutionell zusammenfassen. Daher waren an deren Sitzungen der Innenminister, der Außenminister, sowie der Marinebzw. Kriegsminister beteiligt. Das im Personal aufgestockte Außenministerium ${ }^{28}$ wurde ab Herbst 1800 mit dem kaiserlichen Chefverhandler von Lunéville, Johann Ludwig Baron von Cobenzl, besetzt, der die Funktion als Staats(vize)kanzler ausübte und damit ab August 1801 mit Colloredo eine außenpolitische Doppelspitze für die Habsburger-

26 Regele, Der österreichische Hofkriegsrat, S. 77.

27 Baer, Zum Reformwerk, S. 49-50.

28 Manfred Matzka, Die Staatskanzlei. 300 Jahre Macht und Intrige am Ballhausplatz, Wien 2017, S. 71. 
monarchie bildete. Auf dem Gebiet der praktischen Kriegsführung sollte zwar der Einfluss der Haus-, Hof- und Staatskanzlei und dessen Kanzler eingedämmt werden, was sich v. a. in Thuguts Amtszeit negativ auf militärische Operationen ausgewirkt hatte, doch eine Vernetzung zwischen den politischen und militärischen Behörden wurde durch die oben genannten Maßnahmen trotzdem explizit angestrebt. Mehrere Regulative und auch Anweisungen des Kaisers bestätigen diese Fakten zusätzlich. ${ }^{29}$

Im Falle des Hofkriegsrates wurde in dem genannten Reskript vom 9. Jänner Erzherzog Karl zu dessen Präsidenten ernannt. Dadurch wurde einer der höchsten und erfahrensten Militärs der Monarchie zum direkten Leiter der zentralen Behörde für dessen Kriegsführung und hatte damit für die nächsten Jahre direkten Einfluss auf die Strukturen der Armee der Monarchie. Als erster Schritt wurden die Stellen der Sektionschefs des Hofkriegsrates ausschließlich mit erfahrenem militärischen Personal besetzt und das Personal zur Verwaltung der Akten um einige Stellen erhöht. Zudem wurde in neuen Regulativen als oberste Prämisse ausgegeben, dass die Arbeitsweise wie die eines Kriegsministeriums sein sollte, d. h. dass der Hofkriegsrat nur noch im Hintergrund arbeiten und keinen Einfluss auf die eigentliche Kriegsführung haben sollte.

Der zentrale Teil der militärischen Reformen war das neue System der Rekrutierung. Denn am 4. März 1802 kam es zur Abschaffung der lebenslangen Dienstpflicht (mit einer Übergangszeit bis 1814) und zur Einführung einer achtjährigen Dienstzeit bei der Infanterie, einer zehnjährigen bei der Kavallerie, sowie einer zwölfährigen bei der Artillerie und den technischen Truppen. Zudem wurden auf die gesamte Monarchie aufgeteilte permanente territoriale Militärbezirke geschaffen, in denen die bestehenden Regimenter zukünftig an einem Standort ihre Soldaten rekrutieren konnten. Beide Maßnahmen sollten nicht nur die Rekrutierung vereinfachen, sondern auch den militärischen Dienst attraktiver machen und dadurch die Moral sowie die Schlagkraft der Truppe entscheidend erhöhen. Auch quantitativ wurde die Schlagkraft der Armee verbessert. So hatte die Armee bis zum Jahr 1805 einen Friedensstand von ca. 310.000 Mann, der im Kriegsfall automatisch auf ca. 450.000 erweitert werden konnte. ${ }^{30}$

Die Armee hatte in den folgenden Jahren zwar keine Einsätze, doch für die neu strukturierten politischen Institutionen kam es bereits ab 1801 in der "Reichskrise“ zu einer ersten Bewährungsprobe. So rieten die Mitglieder dieses Gremiums dem Kaiser, den zukünftigen Schwerpunkt auf die Erblande zu legen und das geschwächte Reich vermehrt als Kompensationsmasse für eigene Interessen und zukünftige Verträge zu nutzen, während alle Kräfte für einen Kampf gegen Napoleon konzentriert werden sollten. So wurde am 25. Februar 1803 unter Zustimmung des Kaisers und unter russischer und französischer Kontrolle, den beiden Garantiemächten des Reiches, der Reichsdeputationshauptschluss geschlossen, der zur Säkularisierung und Mediatisierung der 
geistlichen Reichsstrukturen bzw. der Reichsritterschaften und Reichsstädte führte, was die Auflösung der letzten Säulen des realen Kaisertums bedeutete. ${ }^{31}$

Im Gegenzug erarbeiteten sie die wesentlichen außenpolitischen und verfassungstechnischen Voraussetzungen, um Kaiser Franz II. die Annahme des erblichen Kaisertitels von Österreich zu ermöglichen, der diesen Titel am 11. August 1804 als Kaiser Franz I. annahm. Dieser diplomatische Schachzug war auch zeitlich gut gewählt, da Napoleon seinerseits durch die international umstrittene Annahme des Kaisertitels von Frankreich einen Ausgleich mit der Habsburgermonarchie suchen musste. Daher war Napoleon der erste Monarch Europas, der Kaiser Franz II./I. in diesem Amt anerkannte, was einen großen außenpolitischen Erfolg bedeutete. Zudem ermöglichte dieser Titel, die Habsburgermonarchie von einer monarchischen Ständeunion von Einzelstaaten zu einem geeinten Kaisertum aufzuwerten, was damit eine Ausbreitung der Einflussnahme Napoleons auf die einzelnen Territorien der Monarchie verhinderte (so wie dies bereits im Reich der Fall gewesen war). Damit wertete diese symbolische Klammer die gesamte Habsburgermonarchie auch außenpolitisch zu einem gleichwertigen Partner Frankreichs oder dem Zarenreich auf. Aufgrund dieser Tatsache waren die Jahre nach dem Zweiten Koalitionskrieg auch in außenpolitischer Hinsicht ein Erfolg. ${ }^{32}$

In Verbindung mit diesen außenpolitischen Reformen und Umstrukturierungen stand die Geld- und Devisenbeschaffung. Das größte Problem in dieser Hinsicht war die exorbitante Schuldenlast der Monarchie. Sie belief sich im Jahr 1801 bereits auf 613.195.000 Gulden, was gegenüber einem Stand von 390.130.000 Gulden (1793) eine Erhöhung von 76 Prozent bedeutete. Auch in Friedenszeiten wurde auf diesem Gebiet wenig zur Verbesserung der Gesamtlage getan, da die Subsidien Großbritanniens wegfielen und als einziger Ausweg die Notenpresse in Gang gesetzt wurde. Damit sollten die alten Schulden aus den früheren Kriegen bewältigt bzw. die Reformen finanziert werden. Doch dies hatte wiederum eine hohe Inflation zur Folge, was die Monarchie in jenen Jahren an den Rand ihres finanziellen Ruins brachte. Eine längere Friedensperiode mit neuen Kreditgebern aus dem Ausland hätte hierfür sicherlich Entlastung geschaffen. ${ }^{33}$

Um eine Verbesserung dieser Lage zu ermöglichen, arbeiteten Cobenzl und Colloredo an einer außenpolitischen Annäherung an Napoleon, um damit eine erneute diplomatische Kehrtwende zu vollziehen und ein Mächtegleichgewicht wie in der Zeit vor 1789 herstellen zu können. Doch der russische Zar hintertrieb diese Bemühungen über seine Gesandten in Wien, wodurch diese Gespräche nie intensiviert werden konnten. Zudem war bereits im Mai 1803 der 1802 in Amiens geschlossene Frieden zwischen Großbritannien und Frankreich gescheitert, wodurch sich die Habsburgermonarchie zur erneuten Rüstungen und zu Geldausgaben genötigt sah. So steuerte die europäische Politik erneut aufeinen Krieg zu und die Habsburgermonarchie musste trotz unvoll

31 Gottfried Mraz, Österreich und das Reich 1804-1806. Ende und Vollendung, Wien 1993, S. 25-27.

32 Ebd., S. 32-33.

33 Karl A. Roider, Austria's Road to Austerlitz, in: Kinley Brauer/William E. Wright (Hrsg.), Austria in the Age of the French Revolution 1789-1815, Minneapolis 1990, S. 11-24, hier S. 12-13. 
ständig umgesetzter Reformen und stark verschuldeten Staatshaushaltes bald wieder einen Krieg führen. ${ }^{34}$

\subsection{Der Dritte Koalitionskrieg und der Weg nach Pressburg}

Da Napoleon in den Jahren 1804/05 Großbritannien mit einem Invasionsheer erobern wollte, kam auch aus London großer diplomatischer Druck auf die außenpolitische Abteilung der Staatskanzlei zu. Da sich die Monarchie, wie bereits dargestellt, in einer finanziellen und politischen Krise bzw. im Reformstatus befand, arbeitete Cobenzl an Alternativen zu einem erneuten Krieg. Ein Bündnis mit Frankreich wäre in jenen Jahren definitiv eine passende Option zur Achse London - St. Petersburg gewesen, doch sowohl der Kaiser, als auch einige Gruppierungen am kaiserlichen Hof bzw. in den außenpolitischen Behörden blockierten wegen des Einflusses des Zaren weitere Verhandlungen in diese Richtung. So musste erneut dem diplomatischen Druck der Verbündeten nachgegeben werden und nach bereits wenigen Wochen kam es im Dezember 1804 zu einem Bündnis zwischen dem Zarenreich und dem Kaisertum Österreich. Dieses Bündnis, in das Großbritannien 1805 noch einbezogen werden sollte, hatte den Vorteil, dass Napoleon durch diese erneute außenpolitische Trendwende der Habsburgermonarchie überrascht wurde und vorläufig keine Gegenmaßnahmen einleiten konnte. Zudem wurde es dadurch möglich, dass bereits ab Frühsommer 1805 Optionen für einen Feldzug eruiert wurden und die Armee auf den Kriegsstand vorbereitet werden konnte. ${ }^{35}$

Doch die wenigen Monate für die Vorbereitungen beinhalteten auch einige wesentliche Nachteile und Risiken, denn die Aufrüstung der im Umbau befindlichen Armee verlief schleppend und die Reformen waren zum Teil noch nicht komplett umgesetzt geworden. Zudem war auf der Ebene der agierenden militärischen und politischen Behörden in Bezug auf diplomatische Abläufe und Gespräche noch immer keine reibungslose Kommunikation etabliert worden, was viele Missverständnisse förderte. Ein Beispiel dafür waren die Besprechungen zu den Kriegsvorbereitungen. Diese fanden weitgehend ohne Erzherzog Karl statt, der bereits im Frühjahr 1805 wegen Streitigkeiten über den Oberbefehl, die Reformen und die Stellung des Kaiser und einzelner Personen im Kriegsfall als Hofkriegsratspräsident entlassen wurde und damit dem militärischen Beraterkreis weitgehend nicht mehr zur Verfügung stand. Lediglich über direkte Kontakt zu seinem Bruder Franz II./l. bzw. über seine formelle Stellung als Kriegsund Marineminister konnte der Erzherzog einen minimalen Einfluss geltend machen. In diesen persönlichen Besprechungen riet er von einem Krieg vor dem Jahr 1806 ab, was in Verbindung mit den vorher genannten Tatsachen die komplexe politische Lage innerhalb der Monarchie und den geringen Vorbereitungsstand auf einen neuen Krieg veranschaulicht. 
Doch in Wien hatte sich bereits im Sommer 1805 die Kriegspartei durchsetzen können, was mit der Ernennung von General Karl Mack von Leiberich zum Oberbefehlshaber der Armee eindeutig erkennbar ist. Denn trotz seiner Unerfahrenheit und den zweifelhaften taktischen Kompetenzen, die weitgehend auf seinem Rückzug aus Süditalien vor französischen Truppen und der darauffolgenden Gefangennahme im Kriegsjahr 1800 basieren, bekam dieser General den Oberbefehl zugesprochen, da er sich dazu bereit erklärt hatte, einen Angriffskrieg gegen Frankreich und seine Verbündeten zu führen. Diese Fakten bezeugen daher zwar einerseits eine veränderte Einstellung der meisten Entscheidungsträger, schnelle zielgerichtete Maßnahmen für einen erfolgreichen Krieg umzusetzen, aber andererseits auch den weitreichenden Einfluss der politischen Führung auf militärische Entscheidungsträger, was sich bereits in der Vergangenheit als nicht zielführend erwiesen hatte. ${ }^{36}$ Dies wurde auch durch die Ernennung von Erzherzog Karls Nachfolger im Hofkriegsrat ersichtlich. Denn mit Maximilian Graf Baillet von Latour wurde ein erfahrener General an die Spitze dieser Behörde gesetzt, der diesen Kurs ebenso unterstützte. ${ }^{37}$

Mack, der sich bisher v. a. als kompetenter Organisator einen Namen machen konnte, bemühte sich, diese Stärke nach seinem Amtsantritt bei den Streitkräften einzubringen, indem er noch im Frühjahr 1805 eine Reform der Infanterieregimenter durchführte, was die seit 1701 (!) geltende Zusammensetzung der Einheiten veränderte und sie damit zumindest in der Theorie flexibler und schlagkräftiger machte. Obwohl noch immer keine flexiblen Formationen wie Divisionen und Korps geschaffen wurden, sollte durch diese Neuorganisation eine schnellere Angriffskriegsführung möglich werden. Ähnliche Maßnahmen und Reformen gab es auch durch verbesserte Dienstvorschriften bei der Kavallerie und der Artillerie, was einen gewissen Abschluss von Erzherzog Karls Reformen darstellte. Doch von einer modernen Massenheerorganisation war die kaiserliche Armee nicht nur weiterhin weit entfernt. Im Gegenteil beinhaltete sie in Verbindung mit den nach wie vor noch nicht komplett umgesetzten Reformen von Erzherzog Karl viele Gefahren und Unsicherheiten. ${ }^{38}$

Trotzdem gelang mit dem Einmarsch in Bayern (Ende August 1805) eine erneute Überraschung, auf die konsequenterweise die Kriegserklärung vom 23. September an Frankreich erfolgte. Innerhalb weniger Tage wurde fast ganz Bayern besetzt und die Überraschung wurde zu einem vorläufig großen militärischen Erfolg. Doch Napoleon reagierte schnell und entsandte eine Armee an den Rhein, während nach der vollständigen Besetzung die Bewegungen der habsburgischen Verbände stagnierten. Der ursprünglich vorgesehene Plan, mit einem für die französische Seite unerwarteten Hauptstoß über Norditalien dieses Gebiet ebenso zu besetzen, konnte trotz eines Sieges von Erzherzog Karl in der Schlacht von Caldiero (29.-31. Oktober) nicht vollzogen werden, da Napoleon seine vereinigte Armee schneller in Marsch setzte als von den Planungsbehörden in Wien erwartet worden war. Dieser kreiste die ohne russische Hil-

36 Roider, Austria's Road to Austerlitz, S. 16-18.

37 Regele, Der österreichische Hofkriegsrat, S. 77.

38 Christopher Duffy, Die Schlacht bei Austerlitz: Napoleons größter Sieg, München 1979, S. 36-39. 
fe zu weit vorgestoßene Armee von Mack und dem symbolischen Oberbefehlshaber Erzherzog Ferdinand von Österreich-Este mit einer doppelten Übermacht bei UIm ein (16.-19. Oktober, ca. 72.000 gegen 150.000 Mann), was bereits am dritten Tag der Belagerung zur Kapitulation der österreichischen Truppen und zur Vernichtung der ganzen Armee führte. Da den französischen Truppen nun der Weg nach Wien freistand, musste Erzherzog Karl seinen Vormarsch in Italien abbrechen und in Eilmärschen in dieses Gebiet zurückkehren. Doch in der Schlacht bei Dürnstein (11. November) konnte ein Heer, das aus russischen und aus bei UIm ausgebrochenen österreichischen Truppenteilen bestand, einen Flügel der französischen Armee schlagen. ${ }^{39}$

Dieser gemeinsame Erfolg verschaffte den russischen Streitkräften weitere Zeit zum Aufmarsch. Doch deren Generalität wagte aufgrund von Abstimmungsschwierigkeiten mit der kaiserlich-habsburgischen Führung vorerst keine größere Schlacht, was zur Folge hatte, dass sie ihr Heer nach Mähren ausweichen ließen. Daher war Wien ungeschützt und konnte von Napoleon und seinen Truppen bereits am 13. November erobert werden. Doch der strategische Wert der Stadt war wesentlich geringer als von Napoleon erwartet, da die kaiserlichen Behörden bereits nach Olmütz (tsch. Olomouc) und Teschen (tsch. Těšín, pol. Cieszyn) evakuiert worden waren, was deren Handlungsfähigkeit weitgehend erhielt. So hatte die Eroberung der Stadt noch keine automatische Niederlage für die russisch-österreichische Koalition bedeutet. Doch die russischen Kommandeure ließen sich in der Nähe von Brünn auf eine Entscheidungsschlacht in einem Dorf namens Austerlitz (tsch. Slavkov u Brna) ein, ohne auf die Hilfe von Erzherzog Karl und seinen Bruder Erzherzog Johann zu warten. Daher beteiligten sich nur ca. 16.000 österreichische Soldaten auf der Seite der Koalition, die ca. 87.000 Mann in die Schlacht führen konnten (2. Dezember 1805). Nach anfänglichen Erfolgen gelang es Napoleon am sogenannten Pratzeberg eine Entscheidung herbeizuführen, die innerhalb kurzer Zeit einen fluchtartigen Rückzug der Verbündeten auslöste, was hohe Verluste zur Folge hatte. Daher wurde diese Schlacht zu einem der größten Siege Napoleons. Die Gründe für die Niederlage der Verbündeten lagen v. a. in der Organisationsschwäche und den fehlenden taktischen Fähigkeiten der russischen Kommandeure. Die österreichischen Verbände hatten insgesamt ca. 3.500 Mann Verluste erlitten und einige Berichte aus der Schlacht zeigen, dass ihre Kampfweise nur wenig Anteil an der Niederlage hatte. Doch ihre geringe Anzahl hatte keine verändernde Auswirkung auf die Gesamtniederlage. ${ }^{40}$

In den folgenden Tagen trafen bereits die Truppen Erzherzog Karls ein, die sowohl in Mähren als auch in Böhmen einige kleinere Erfolge erringen konnten. Aber nach dem Rückzug der russischen Streitkräfte Mitte Dezember war die Situation nahezu aussichtslos geworden. Verlassen von seinen Verbündeten musste Kaiser Franz II./I., obwohl er noch eine intakte Armee zur Verfügung hatte, am 6. Dezember einen Waffenstillstand

39 Richard Basset, For God and Kaiser. The Imperial Austrian Army from 1619 to 1918, New Haven 2015, S. $235-241$. 
mit Napoleon schließen, der in den folgenden Wochen zu dem für die österreichische Seite so folgenschweren Frieden von Pressburg werden würde. ${ }^{41}$

\section{Der Friedensvertrag von Pressburg und seine Folgen für das Kaisertum Österreich}

\subsection{Diplomatischer Prolog}

Das vorangegangene Kapitel verdeutlicht, dass außer der schweren Niederlage von Ulm und der militärisch unbedeutenden Eroberung Wiens keine weiteren größeren Rückschläge für das Kaisertum Österreich bis Dezember 1805 eingetreten waren und die Armee definitiv Fortschritte im Umgang mit der französischen Armee gezeigt hatte. Militärische Reserven wären auch nach Austerlitz noch vorhanden gewesen und mit den Erzherzögen Karl und Johann fähige militärische Kommandeure, diese zu führen. Trotzdem war aufgrund der Gesamtlage jeder weitere Widerstand zwecklos geworden und dem Kaiser wurde klar, dass der folgende Friede die bisher größte Niederlage bedeuten würde. Dies macht deutlich, dass die zentralen Faktoren dafür nicht nur auf militärischer Ebene, sondern auch auf politischer Ebene und auf der Verbindungsebene zum Militär untersucht werden müssen.

Die diplomatischen Gespräche zur Beendigung des Krieges hatten bereits wenige Wochen nach Ausbruch der Feindseligkeiten eingesetzt. Ein erster entscheidender Rückschlag für das Kaisertum waren die gescheiterten Bemühungen Preußen in den Krieg gegen Napoleon zu bringen, was ein wichtiger Eckstein im Bündnis gewesen wäre. Der Grund für die Neutralität Preußens lag an dem überfallsartigen Vorstoß des habsburgischen Heeres auf Bayern, das ein sofortiges politisches Werben von Napoleon um Preußen auslöste. Währenddessen konnte die außenpolitische Führung der Monarchie keine klare Haltung zu Preußen aufbauen. Hierin zeigt sich auch der vielleicht größte Fehler auf der politischen Ebene des Kaisertums im Jahr 1805. Die Entscheidungsträger arbeiteten meist gegeneinander und der Kaiser war trotz einiger Anweisungen nicht in der Lage, dies zu verbessern. Die Schaffung des Staats- und Konferenzministeriums und die Funktionen von Colloredo und Cobenzl hatten dies nicht ändern können. Im Gegenteil, auch in diesen Gremien kam es zu einigen Unstimmigkeiten, was die außenpolitische Lage spätestens nach dem Fall Wiens und der damit verbundenen Evakuierung der Behörden chaotisch werden ließ.

Wie Kriegsführung mit Politik und Propaganda optimal verbunden werden konnte, wurde in den Monaten des Jahres 1805 von der französischen Seite aufgezeigt. So gab es bereits Anfang Oktober ein erstes Projekt bzw. Memorandum von Außenminister Charles-Maurice de Talleyrand-Périgord in Straßburg (17. Oktober), ${ }^{42}$ bzw. auch eines

41 Duffy, Die Schlacht, S. 117-118.

42 Rudolfine Freiin von Oer, Der Friede von Pressburg. Ein Beitrag zur Diplomatiegeschichte des napoleonischen Zeitalters (Neue Münstersche Beiträge zur Geschichtsforschung 8), Münster 1965, S. 19. 
in München (27. Oktober) ${ }^{43}$ und ein zweites Friedensprojekt in Wien (1. Dezember), ${ }^{44}$ welche alle klar formulierte Inhalte hatten. Obwohl alle an den unterschiedlichen Forderungen der Kriegsparteien scheiterten, zeigen sie einerseits die enge räumliche und institutionelle Bindung der französischen Diplomatie an das Heerwesen und andererseits auf der Gegenseite die Starrheit der österreichischen Institutionen, welche funktionell zu unflexibel waren und kaum interdisziplinär arbeiteten. Kaiser Franz II./I. versuchte daher nach dem Verlust von Wien neue Personen als bestimmende Figuren für die Verhandlungen zu positionieren, was mit Johann Philipp Graf von Stadion und General Lieutenant Ignaz Graf von Gyulai auch gelang. Beide sollten sich mit den nach Olmütz gezogenen Behörden und dem Kaiser austauschen und einen baldigen Frieden vorbereiten. Dies hatte zwar einen gewissen Autoritätsverlust für Colloredo und Cobenzl zur Folge, allerdings sicherte dies die außenpolitische Handlungsfähigkeit der Monarchie. So war Stadion als Gesandter in St. Petersburg einer der Baumeister der Dritten Koalition gewesen und damit in gewisser Sicht vorbelastet, was sich in einer vorläufigen Fortsetzung des Krieges abzeichnete. Dennoch wurde ihm nach der Niederlage von Austerlitz klar, dass eine Fortführung des Kampfes keinen Sinn hatte und die Ressourcen für einen eventuellen nächsten Krieg aufgespart werden sollten. Daher leitete Stadion nach dem 2. Dezember in zügigem Tempo Friedensgespräche ein, um eine weitere Verschlechterung der Gesamtlage zu verhindern. ${ }^{45}$

\subsection{Der Friedensvertrag}

Für Napoleon war der entscheidende Sieg von Austerlitz die Möglichkeit, auf politischer Ebene seine Forderungen durchzusetzen. Trotzdem war die Lage zum Zarenreich und Großbritannien noch keinesfalls komplett zugunsten des französischen Kaiserreiches geklärt, was Napoleons großes Interesse an einer baldigen Unterzeichnung eines Friedens mit dem Habsburgerreich erklärt. Der Vertrag zwischen Frankreich und Preußen in Schönbrunn (15. Dezember 1805), in dem die Hohenzoller auf Neuchâtel (dt. Neunburg) verzichteten, das an Frankreich fiel, während das Fürstentum Ansbach Bayern zugeschlagen wurde und Hannover an Preußen kam, ${ }^{46}$ bzw. die Brünner Verträge mit den restlichen süddeutschen Staaten, ermöglichten die letzten Weichenstellungen, um das Kaisertum Österreich zu isolieren und einen baldigen Frieden vorzubereiten. Da die französischen Diplomaten bereits umfangreich in diese Richtung vorgearbeitet hatten, konnten die Verhandlungen noch vor dem Jahreswechsel aufgenommen werden. Durch die räumliche Nähe zum Schlachtfeld wurde Pressburg als Standort der Verhandlungen auserkoren. ${ }^{47}$

Nach nur wenigen Tagen Verhandlung konnte sich Napoleon und sein Chefverhandler Talleyrand weitgehend durchsetzen und die kaiserlichen Verhandlungsleiter Generalleutnant Joseph Johann Graf von Liechtenstein und Generalleutnant Ignatz Graf von

\footnotetext{
43 Freiin von Oer, Der Friede von Pressburg, S. 47-51.

44 Ebd., S. 104

45 Ebd., S. 77

46 Ebd., S. 152-156.

47 Ebd., S. 131-140.
} 
Gyulai unterzeichneten den Vertrag am 26. Dezember 1805. In insgesamt 34 Artikeln wurde zum dritten Mal in acht Jahren Friede zwischen dem Kaisertum Österreich und dem Kaiserreich Frankreich geschlossen. Nach einer allgemeinen Einleitung, die ähnlich wie in den vorangegangenen Verträgen die Monarchen und die zur Handlung bevollmächtigten Personen aufzählte, wurde in Artikel I. als rein formeller Akt der ewige Friedenswunsch aller Parteien geäußert und bekräftigt. Zudem wurden in Artikel II. die in den vergangenen zwei Friedensverträgen ausgehandelten Gebietsverschiebungen auf dem italienischen Territorium nochmals unterstrichen, da dies die Grundlage für die folgenden Bestimmungen darstellte. Weiterführend war der erste zentrale Eckpfeiler des Friedensvertrages der Verlust der letzten Besitzungen des Kaisertums Österreich in Italien. Venetien, Istrien und Dalmatien (Art. IV.), sowie die Herrschaften Lucca und Piombino (Art. III.) wurden dem napoleonischen Königreich Italien zugeschlagen, was das vorläufige Ende der habsburgischen Herrschaft in diesem Teil Europas bedeutete. Ein weiterer Punkt war der Verlust der Grafschaft Tirol mit den sieben Herrschaften in Vorarlberg, sowie der Fürstentümer Brixen und Trient und kleinerer Gebiete bei Passau, Burgau und Eichstätt, welche allesamt an Bayern (Art. VIII.) fielen. Die vorderösterreichischen Besitzungen in Schwaben und an der Donau wurden zwischen Württemberg und Baden aufgeteilt (ebenfalls Art. VIII.). Die Kurfürstentümer Bayern und Württemberg wurden zu Königreichen erhoben und bekamen noch weitere Gebietszuschläge im süddeutschen Raum zugesprochen (u. a. Augsburg an Bayern in Art. XIII.), wodurch sich das Kaisertum Österreich nicht nur mit gestärkten Gegnern um die Macht im deutschen Raum konfrontiert sah, sondern auch einer weiteren Ostverschiebung seiner Machtbasis. Im Gegenzug bekam es lediglich das Fürstentum Salzburg und das Gebiet Berchtesgaden in Form eines Herzogtums überlassen (Art. X.). Deren Kurfürst wurde mit Würzburg entschädigt, das zu einem neuen Kurfürstentum im mittlerweile unbedeutenden Reich wurde (Art. XI.). Die letzten Artikel umfassten den Umgang und die Zeitspanne für die Ratifikation der Friedensurkunden und bestimmten auch das Zeitfenster des effektiven Austausches aller Länder und Territorien. ${ }^{48}$

Aufgrund der räumlichen Nähe beider Monarchen zum Verhandlungsort unterzeichnete Napoleon bereits am 27. Dezember die französische Ausfertigung des Vertrages in Schönbrunn, während Kaiser Franz II./I. am 30. Dezember die österreichische Variante am selben Ort unterschrieb. Alle Bedingungen traten mit dem Austausch der unterschriebenen Ausfertigungen, die am Neujahrstag 1806 erfolgte, somit bereits in den ersten Wochen jenes Jahres in Kraft. ${ }^{49}$

4.3 Die unmittelbaren Folgen des Pressburger Friedensvertrages und die zweite Reformperiode (1806-1809)

Die Niederlage von 1805 war aufgrund der territorialen Verluste die bis dato folgenreichste und demütigendste für das Habsburgerreich. Lediglich die Bereitschaft, den 
Vertrag von Pressburg schnell und unkompliziert abzuschließen, war die einzige positive Handlung auf habsburgischer Seite, wodurch weitere sinnlose Gebiets- und Truppenverluste vermieden werden konnten. Aufgrund dieser Tatsachen wurden erneut Forderungen nach umfangreichen Reformen laut. Als erster Schritt wurden, so wie nach den vorangegangenen Kriegen, Personalien hinterfragt und neu besetzt. Bereits Ende Dezember 1805 nahm Kaiser Franz II./l. das Rücktrittsgesuch von Außenminister und Staats(vize)kanzler Cobenzl an, der genau wie seine Vorgänger als Leiter der Außenpolitik nach Abschluss des Friedensvertrages all seine Ämter zurücklegte. Als neuer Staatskanzler und Außenminister wurde Graf von Stadion berufen, der bereits seit Colloredos Rücktritt Ende November 1805 den außenpolitischen Kurs der Monarchie bestimmt hatte. Doch personelle Konsequenzen waren noch nicht weitreichend genug. Denn wie bereits dargestellt, waren sowohl die Gremien der Geheimen (Haus-), Hof- und Staatskanzlei, als auch die des eigentlich übergeordneten Staats- und Konferenzministeriums mehrfach in Konkurrenz geraten, was in Verbindung mit den Anweisungen des Kaisers und des Hofkriegsrates zu einer uneinheitlichen außenpolitischen Linie während des Krieges geführt hatte und damit im Endeffekt auch zur Niederlage. Daher wurden in der folgenden Woche mit der Abschaffung der sogenannten außenpolitischen „Doppelspitze” erste strukturelle Reformen umgesetzt. Zudem wurden im Juni 1806 das Außenpolitik- und das Kriegs- und Marinedepartement des Ministeriums aufgelöst, während die Behörde selbst nach nur ca. siebenjähriger Bestandszeit mit Juni 1808 ebenfalls abgeschafft wurde. Stattdessen wurde wieder ein Staatsrat (nun auch Staats- und Konferenzrat genannt) als Beratungsorgan des Kaisers in Form einer direkt untergeordneten Immediatbehörde geschaffen. Diese hatte mit der reinen Beratungsfunktion ihrer fünf Sektionen (darunter auch Krieg/Außenpolitik) wenig Kompetenzen, jedoch wurden mehrere Mitglieder im Laufe der folgenden Jahre als Hofräte in den Hofkriegsrat und in die Sektionen der Staatskanzlei berufen, was ihren Einfluss und die Kontrollmöglichkeiten auf die Außenpolitik und das Militärwesen wesentlich erhöhte. Auch die Staatskanzlei wurde als Immediatbehörde direkt unter den Kaiser gestellt und hatte in Zukunft die alleinige Aufgabe, in Absprache mit dem Monarchen die Außenpolitik der Monarchie zu organisieren. ${ }^{50}$

In all diesen Reformen wird daher deutlich, dass nach der Niederlage von 1805 der Abbau von Bürokratie in den politischen Behörden angestrebt wurde und der verkleinerte Behördenapparat eine Konzentration der politischen Organe auf die Person des Kaisers als deren zentralen Leiter bewirken sollte, um in Kriegszeiten schnelle Entscheidungen umsetzen zu können. Da das als modernes Ministerium arbeitende Staatsund Konferenzministerium abgeschafft wurde, stellten diese Maßnahmen (im Gegensatz zu Preußens Reformen nach ihrer Niederlage von 1806) zwar einen strukturellen Rückschritt dar, doch die Behörden wurden durch die Vereinfachung der Amtswege schneller und damit krisenresistenter. Dies ging daher mit der (außen-)politischen Institutionalisierung des kaiserlichen Amtes und der des Staatskanzlers einher, der als 
Außenminister wie vor 1801 direkten Zugang zum Kaiser hatte und daher Absprachen schneller treffen konnte..$^{51}$

Im Militärapparat der Monarchie wurden nach 1805 ähnliche Reformen umgesetzt. Denn mit der unehrenhaften Entlassung General Macks und der Berufung Erzherzog Karls zum Generalissimus am 11. Jänner 1806 bzw. zum Präsidenten des Hofkriegsrates bei gleichzeitiger Ablösung von Graf Baillet v. Latour wurden auch auf diesem Gebiet als Erstes personelle Veränderungen vorgenommen. Damit verbunden waren allerdings einige sofortige strukturelle Änderungen. Denn der Bruder des Kaisers sollte in Zukunft zur zentralen Person auf institutioneller Ebene werden. Damit er seine Ämter allerdings während seiner Präsenz bei den Truppen in Kriegszeiten bekleiden und ausführen konnte, wurde in diesem Fall von der Reduktion der Behördenstrukturen eine Ausnahme gemacht. So wurde 1806 mit Feldzeugmeister Wenzel Joseph Graf von Colloredo-Mels und Wallsee ein zweiter de facto gleichwertiger Präsident in dieses Amt geholt, der den Bruder des Kaisers zusammen mit den einzelnen Ressortleitern des Hofkriegsrates während Feldzügen in Wien vertreten sollte und der v. a. die politisch-ökonomische Abteilung führte. ${ }^{52}$

Durch diese Doppelspitze konnte in den folgenden Monaten ein hohes Reformtempo umgesetzt werden. Denn in der Folgezeit wurden in einem erneuten Reformprogramm, welches das umfangreichste seit den 1750er/60er-Jahren werden würde, einige Erneuerungen durchgesetzt, die von Erzherzog Karl schon seit Jahren gefordert wurden. Ein wesentlicher struktureller Schritt war die endgültige Umsetzung der Umwandlung des Hofkriegsrates in eine Immediatsbehörde, was bereits vor dem Krieg im März 1805 geschehen war, aber erst im Zuge der Auflösung des Kriegs- und Marinedepartements im Sommer 1806 umgesetzt werden konnte. Auf dieser institutionellen Grundlage konnten innerhalb weniger Monate zahlreiche weitere Reformen relativ zügig beschlossen und umgesetzt werden. ${ }^{53}$

Die erste dieser Reformen war die Einführung der Volksbewaffnung, die gegen den Widerstand des Kaisers erfolgte, da dieser in Krisenzeiten einen Volksaufstand befürchtete, die eine Mobilisierung der Massen für die Armeeführung des Kaisertums ermöglichen sollte. Daher wurde im Jahr 1808 die Aufstellung einer Landwehr bzw. die Aufstellung der nahezu identischen „insurrectio“ in den Ländern der ungarischen Krone und einer "Reservearmee“ in Galizien angeordnet. Dies ebnete einerseits den Weg zu einem geordneten Ersatzwesen der Armee, aber auch zu einer geeigneten Reaktionsund Verteidigungsmöglichkeit im Falle einer erneuten Invasion der habsburgischen Erblande, um eine erneute schwere Niederlage wie im Jahr 1805 verhindern zu können. Das Gesamtvolumen der Aushebungen ermöglichte der Armeeführung, das Heer auf einen theoretischen Kriegsstand von ca. siebenhunderttausend Mann zu bringen, was diese von der Größe ungefähr auf den Mobilmachungsstand der französischen Armee brachte. Dies war einerseits durch die Aufstellung von Reservekadern und Neu-

51 Matzka, Die Staatskanzlei, S. 74.

52 Regele, Der österreichische Hofkriegsrat, S. 31.

53 Ebd., S. 77. 
aushebungen möglich, aber auch durch den im Friedensvertrag gemachten Gefangenenaustausch, durch den die erfahrenen Veteranen der Monarchie wieder zurück in ihren Dienst rücken konnten. Zudem war die Landwehr eine geeignete Möglichkeit, die Bevölkerung in einem Abwehrkampf zu „patriotisieren“.54

Als weitere strukturelle Maßnahme und zur Vorbereitung der "Landwehrreform" wurde bereits im Jahr 1807 ein neues Infanterie- und Kavalleriereglement eingeführt, welche die als gescheitert angesehenen Reformen Macks beseitigen und die letzten Elemente der modernen Kriegsführung einführen sollten. So wurden einerseits die „kleineren" Einheiten bis zur Regimentsebene wie im System vor 1805 beibehalten, andererseits die Abschaffung der bisherigen "großen" Gefechtsformationen, die sogenannte "Ordre de Bataille", angeordnet. Daher kam es zur Aufstellung von neuen Großverbänden über der Ebene der Bataillone- und Regimenter, deren Anzahl mit 78 Infanterie- und 35 Kavallerieregimentern nahezu konstant blieb und die als solide Grundeinheiten erhalten wurden. Die Einteilung in neun Divisionen mit zwei Reservedivisionen und den darüber eingerichteten Korps ermöglichten die Bildung von geschlossenen Kampfverbänden mit Vertretern aus allen Waffengattungen und einer Massierung der Artillerie in großen Batterien, was sowohl den Armeeoberbefehlshabern in einer Schlacht mehr Übersicht bringen und damit eine schnellere Schwerpunktverlagerung innerhalb des Gefechts ermöglichen sollte. Den untergeordneten Offizieren sollte darüber hinaus mehr Verantwortung und Selbstständigkeit gegeben werden, was sich insgesamt auf eine aktivere und offensivere Kriegsführung auswirken sollte..$^{55}$

Beide Reglements und das System der Volksbewaffnung waren auf lange Sicht sehr erfolgreich und sollten bis 1860 bzw. 1859 in Kraft bleiben, während die Einteilung in die beschriebenen Gefechtsformationen bis $1918 \mathrm{im}$ Wesentlichen erhalten blieb. Von all diesen Maßnahmen erwarteten sich der Kaiser und die militärische Führung einen entscheidenden Impuls, um Napoleon endlich schlagen zu können. Dafür verhielt sich die Monarchie im Vierten Koalitionskrieg neutral, der erneut mit einem Sieg Napoleons enden sollte, was aufgrund umsichtigen Taktierens von Stadion gelungen war und damit auch einen Erfolg in einer schwierigen außenpolitischen Phase darstellte. ${ }^{56}$

Nach einer etwas mehr als drei Jahre anhaltenden Friedens- und Umstrukturierungsphase wurden Anfang 1809 von Stadion erneut die Weichen für einen Krieg gestellt. Doch die außenpolitische Leitung machte wieder den Fehler, einen Krieg ohne potente Verbündete zu führen. Dieser Fünfte Koalitionskrieg wurde daher, trotz einiger Erfolge von Erzherzog Johann und Erzherzog Karl in den Schlachten von Sacile (16. April) bzw. bei Aspern-Esslingen (21./22. Mai) und einem anfänglich erfolgreich initiierten Volksaufstand in Tirol, zu einem erneuten Desaster und ging durch eine Invasion des Kaisertums und der wiederholten Besetzung Wiens auf nahezu identische Weise wie 1805 verloren. Bei Deutsch-Wagram kam es am 5./6. Juli zur Entscheidungsschlacht, die Erzherzog Karl trotz geringerer Verluste an Toten und Verwundeten verlor. 
Nach dem Waffenstillstand von Znaim (tsch. Znojmo) kam es im darauffolgenden Friedensvertrag von Schönbrunn (Wien, 14. Oktober) zu einer erneuten Reduzierung des Staatsgebietes. ${ }^{57}$ Neben dem Verlust von Gebieten wie Dalmatien und Istrien, sowie Salzburg, Berchtesgaden, dem Innviertel, Westgalizien und Tarnopol, musste die Armee auf 150.000 Mann verringert werden und zum ersten Mal musste das Kaisertum Kontributionen an Frankreich leisten. In den folgenden Jahren musste der seit dem Rücktritt Stadions (Oktober 1809) amtierende Außenminister und Staatskanzler Fürst Klemens Wenzel Lothar von Metternich sogar den Ausgleich mit Napoleon suchen und in den folgenden Jahren ein Bündnis eingehen.

Doch Metternich wusste bereits, dass die Herrschaft Napoleons, der sich mittlerweile in einem Vielfrontenkrieg befand, ihren Zenit überschritten hatte und ein weiteres Durchhalten bzw. geschicktes Taktieren am Ende einen Sieg ermöglichen würde. Daher setzte er auf die meisten der zwischen 1792 und 1809 umgesetzten Reformen, die sowohl in der verkleinerten Armee, als auch in den außenpolitischen Institutionen erhalten und noch weiter optimiert wurden, was zusammen mit dem Staatsbankrott von 1811 die nötigen militärischen und finanziellen Möglichkeiten schuf, um einige Jahre später einen erneuten Krieg gegen Napoleon zu führen. Am ab 1813 laufenden „Befreiungskrieg" einiger europäischer Mächte gegen Napoleon beteiligte sich das Kaisertum daher erst nach intensiver Absprache und Planung mit der Armeeleitung und einer langen Vorbereitungsphase. Zudem gelang es Metternich im Herbst 1813, die Monarchie als entscheidende militärische und politische Macht in ein europaweites Offensivbündnis mit den Mächten Russland, Preußen, Schweden und Großbritannien, sowie auch anderen kleineren Territorien Europas zu integrieren. Dies ermöglichte den entscheidenden Sieg in der Völkerschlacht bei Leipzig (16.-19. Oktober), welche unter der Leitung von Feldmarschall Karl Philipp von Schwarzenberg erfolgte, der Napoleon mit einer Zermürbungstaktik unter der maßgeblichen Beteiligung von kaiserlich-habsburgischen Truppen schlug. Dadurch war es den Verbündeten im Folgejahr möglich, eine erfolgreiche Invasion in Frankreich zu starten und Paris einzunehmen. Dies führte auf dem Wiener Kongress bzw. den beiden Pariser Friedensverträgen 1814/15 zur Wiedererlangung der meisten in der Vergangenheit verlorenen Territorien und damit auch zur Erlangung des einstigen Großmachtstatus. ${ }^{58}$

\section{Fazit}

Die dargestellten Fakten dieser Arbeit bestätigen die eingangs formulierte Annahme, dass die Phase der ersten drei Koalitionskriege für die Habsburgermonarchie mehr als eine Übergangsphase mit vielen Niederlagen und politischer und militärischer Stagnation war. Es konnte bewiesen werden, dass jene Jahre genutzt wurden, um wesentliche Maßnahmen zu setzen, um die Leistung der militärischen und außenpolitischen Ressorts der Monarchie nachhaltig zu verbessern. Diese Verbesserungen waren auch die

57 Donald D. Horward, The Proud Adversaries: Masséna And The Archduke Charles, in: Kinley Brauer/William E. Wright (Hrsg.), Austria in the Age of French Revolution. 1789-1815, Minneapolis 1990, S. 25-46, hier S. 42-44.

58 Baer, Zum Reformwerk, S. 54-55. 
zentralen Mechanismen, um die Habsburgermonarchie als entscheidenden „Player" in der europäischen Politik zu erhalten. Die in der Hypothese dargelegte Auffassung, dass diese Veränderungen evolutionär erfolgten, konnte über den Nachweis einer mehrstufigen Reform in den Jahren vor, während und nach den ersten drei Koalitionskriegen ebenso dargelegt werden.

Mehrere Maßnahmen belegen dies für den Militärapparat der Monarchie. Diese wurden sowohl in der Ausrüstung, als auch in der Gefechtsweise/Organisation der Truppe, sowie im institutionell dahinter stehenden Hofkriegsrat durchgeführt, was die hohe Reichweite und den Umfang all dieser Änderungen veranschaulicht. Doch da sich im Jahr 1792 die Kampfweise und Ausrüstung der Armee keineswegs als veraltet und überholt präsentiert hatte, sondern meist sogar noch entscheidende Siege ermöglicht hatte, wurden nach dem Ersten Koalitionskrieg vorerst nur die dringendsten Maßnahmen umgesetzt. Daher wurden als Erstes die Reformen in der Ausrüstung durchgeführt, während strukturelle Reformen erst in der Phase vor und nach dem Dritten Koalitionskrieg stattfanden. Innerhalb dieser ab 1797 gestarteten Maßnahmen ist daher auch ein gewisser Ablauf zu erkennen. Damit einher ging die Praxis, die Reformen vorrangig in Friedenszeiten durchzuführen, was den Vorteil hatte, dass es zu keiner Unterbrechung bzw. Störung der militärischen Abläufe in Kriegszeiten kam. All diese Faktoren ermöglichten, dass die kaiserlich-habsburgische Armee in den ersten zwei Koalitionskriegen eine zentrale Rolle bei der Abwehr der Revolutionsarmeen spielen konnte und es dadurch einen größeren Handlungsspielraum für die außenpolitische Führung der Monarchie in den Friedensverhandlungen gab. Die weiterführende Untersuchung all der genannten Maßnahmen ergab zwar keinen direkten Einfluss der Friedensverträge auf den militärischen Apparat der Monarchie, doch die schnelle Planung und Durchführung der Reformen in den Friedenszeiten belegt, dass die Rückschläge neue Impulse für eine Veränderung gesetzt und somit indirekt auf die Erneuerung Einfluss hatten. Einzig der nach jedem Krieg ausverhandelte Gefangenenaustausch war ein zentrales Element aller Friedensverträge, was sich nach den hohen Verlusten an Gefangenen im Jahr 1805 direkt auf die Schlagkraft der Monarchie auswirkte und ein wesentliches Element zu deren Erhaltung beitrug. Aufgrund all dieser Tatsachen waren die militärischen Kapazitäten des Kaisertums Österreich auch nach vielen Jahren des Krieges zur Regeneration weitgehend ausreichend, was nach der erneuten Niederlage von 1809 und einer Friedensphase bis 1813 in den Befreiungskriegen in einem endgültigen militärischen Sieg gegen Napoleon endete.

Mit denselben Methoden lassen sich die oben genannten Annahmen auch in den außenpolitischen Strukturen bzw. ihren evolutionären Veränderungen beweisen. Am Beginn des Ersten Koalitionskrieges erforderten die weitgehend funktionierenden auBenpolitischen Strukturen lediglich marginale Anpassungen. Dafür sprechen die Abwehrerfolge und die weitgehend handlungsfähige Koalition der ersten Jahre. Erst mit dem Zerfall dieser Ersten bzw. der kurz darauf folgenden Zweiten Koalition mussten auch strukturelle Maßnahmen gesetzt werden, um eine außenpolitische Isolation der Monarchie zu vermeiden. Tatsächlich lag das außenpolitische Scheitern mehr an den 
Handlungen einzelner Personen, wie den Kanzlern Thugut, Cobenzl, Colloredo, Stadion usw., die meist ohne große Planung mit der militärischen Führung die Habsburgermonarchie in den Krieg führten, was dadurch potentielle Bündnisse mit anderen Mächten verhinderte. Daher wurde nach fast jedem Krieg die außenpolitische Leitung ausgetauscht, was jedoch nur kurzfristig außenpolitischen Aufschwung ermöglichte. Die Behördenstrukturen dahinter funktionierten allerdings weiter und konnten so in den Jahren nach dem Zweiten Koalitionskrieg sogar zu modernen Ministerien weiterentwickelt werden. Durch ihre verbesserte Arbeitsweise wurde es in der Folgezeit möglich, einige weitere entscheidende Maßnahmen und Reformen außenpolitisch durchzusetzen. Ein direkter Einfluss der Verhandlungsleiter der Monarchie ist daher auch auf die Friedensverträge zu erkennen. Denn sie waren im Stande, trotz aller Rückschläge und Gebietsverluste, die zunehmende Arrondierung der habsburgischen Erblande zu erreichen und diese in den folgenden Jahren zu konsolidieren. Dies zog sich als Leitlinie durch alle Verträge der napoleonischen Ära und stellte damit einen entscheidenden Erfolg in jenen Krisenjahren dar. Ein weiterer zentraler Eckpunkt der Maßnahmen und eine Folge des Zweiten Koalitionskrieges war der im Jahr 1804 eingeführte Kaisertitel für das Kaisertum Österreich. Dieser ermöglichte eine langfristige symbolische Klammer um die Erblande zu spannen und damit eine gemeinsame Identität für die Monarchie zu schaffen. Dies und die folgende außenpolitische Institutionalisierung des kaiserlichen Amtes führten trotz einer darauffolgenden behördlichen Rückentwicklung zu einer gesamten Stärkung der Zentralmacht und gaben trotz aller Krisen einen neuen Auftrieb für die außenpolitischen Bewegungen der Monarchie. Daher war es auch in den Krisenjahren möglich, einen Großteil der Verbündeten zu erhalten bzw. diese im Jahr 1813 in ein neues Bündnis zu integrieren. Denn wie bereits dargestellt, war es in jenem Jahr erneut möglich, ein europaweites Bündnis mit den Großmächten Preußen, Russland und Großbritannien einzugehen und damit nach all den Rückschlägen der vergangenen Jahre einen außenpolitischen Sieg gegen Napoleon zu realisieren.

\section{Literatur}

Baer, Fritz, Zum Reformwerk des Kriegsministers Generalissimus Erzherzog Karl, in: Fritz Hans Baer (Hrsg.), Die k.k. Österreichische Armee im Kampf gegen die französische Revolution und Napoleon I., Wien 1989, S. 45-64.

Basset, Richard, For God and Kaiser. The Imperial Austrian Army from 1619 to 1918, New Haven 2015.

Broucek, Peter, Zum Kriegsbild und zur Heereskunde der Österreichischen Armee im Zeitalter Napoleons I., in: Fritz Hans Baer (Hrsg.), Die k.k. Österreichische Armee im Kampf gegen die französische Revolution und Napoleon I., Wien 1989, S. 5-44.

Duffy, Christopher, Die Schlacht bei Austerlitz: Napoleons größter Sieg, München 1979.

Fahrmeir, Andreas, Revolutionen und Reformen. Europa 1789-1850, München 2010.

Fehrenbach, Elisabeth, Vom Ancien Régime zum Wiener Kongress (Oldenbourg Grundriss der Geschichte 12), München 2008. 
Fiedler, Siegfried, Taktik und Strategie der Kabinettskriege 1650-1792, Augsburg 2005.

Fiedler, Siegfried, Taktik und Strategie der Revolutionskriege 1792-1848, Augsburg 2005

Horward, Donald D., The Proud Adversaries: Masséna And The Archduke Charles, in: Kinley Brauer/William E. Wright (Hrsg.), Austria in the Age of French Revolution. 1789-1815, Minneapolis 1990, S. 25-46.

Matsch, Erwin, Geschichte des auswärtigen Dienstes von Österreich(-Ungarn) 1720-1920, Graz 1980.

Matzka, Manfred, Die Staatskanzlei. 300 Jahre Macht und Intrige am Ballhausplatz, Wien 2017.

Mazohl, Brigitte, Vom Tod Karls VI. bis zum Wiener Kongress (1740-1815), in: Thomas Winkelbauer (Hrsg.), Geschichte Österreichs, Stuttgart 2016, S. 290-358.

Oer, Rudofine Freiin von, Der Friede von Preßburg. Ein Beitrag zur Diplomatiegeschichte des napoleonischen Zeitalters (Neue Münstersche Beiträge zur Geschichtsforschung 8), Münster 1965.

Ortenburg, Georg, Die Waffen der Revolutionskriege 1792-1848, Augsburg 2005.

Reinerman, Alan J., The Papacy, Austria, And The Anti-French Struggle In Italy. 1792-1797, in: Kinley Brauer/William E. Wright (Hrsg.), Austria in the Age of French Revolution. 1789-1815, Minneapolis 1990, S. 47-68.

Roider, Karl A., Austrias's Road to Austerlitz, in: Kinley Brauer/William E. Wright (Hrsg.), Austria in the Age of French Revolution. 1789-1815, Minneapolis 1990, S. 11-24.

Vocelka, Karl, Glanz und Untergang der höfischen Welt. Repräsentation, Reform und Reaktion im habsburgischen Vielvölkerstaat (Österreichische Geschichte 1699-1815), Wien 2001.

Walder, Ernst (Hrsg.), Napoleonische Friedensverträge. Campo Formio 1797 - Lunéville 1801 - Amiens 1802 - Preßburg 1805 - Tilsit 1807 - Wien - Schönbrunn 1809, Bern 1973.

Winkelbauer, Thomas, Die Habsburgermonarchie vom Tod Maximilians I. bis zum Aussterben der Habsburger in männlicher Linie (1519-1740), in: Thomas Winkelbauer (Hrsg.), Geschichte Österreichs, Stuttgart 2016, S. 159-289.

Patrick Plaschg ist Student im Masterstudium Geschichte und Bachelor Archäologie an der Universität Innsbruck. Patrick.Plaschg@student.uibk.ac.at 


\section{Zitation dieses Beitrages}

Patrick Plaschg, Die Rolle der Habsburgermonarchie in den ersten drei Koalitionskriegen (1792-1809). Eine Fallstudie zur Darstellung der Überwindung von militärischen und politischen Krisen in der Neuzeit, in: historia.scribere 10 (2018), S. 401-429 [http://historia.scribere.at], eingesehen 19.6.2018 (=aktuelles Datum).

(C) Creative Commons Licences 3.0 Österreich unter Wahrung der Urheberrechte der Autorlnnen. 
